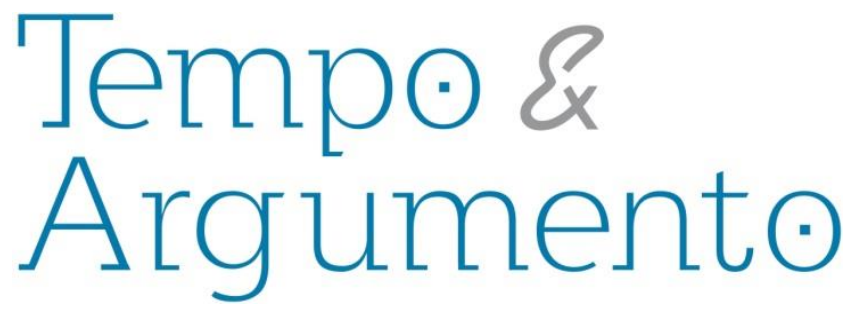

\title{
"Ayudar a aquellos artistas que transformaron la canción en un arma de lucha": o papel das Juventudes Comunistas na difusão da Nova Canção Chilena (1968-1973) ${ }^{1}$
}

\begin{abstract}
Resumo
Em uma época marcada pela expectativa revolucionária, muitos jovens partidários do socialismo elegeram a arte como trincheira privilegiada na luta por uma nova sociedade. No campo musical, os anos 1960 viram emergir na América Latina a figura do músico popular engajado, que passou a utilizar seu ofício para se posicionar frente às questões políticas, sociais e econômicas de seu tempo. No Chile, a canção engajada encontrou respaldo no Partido Comunista, que foi o principal responsável pela produção e circulação do repertório ligado à Nova Canção Chilena até os anos 1980. Enfocando o período anterior ao golpe militar de 1973 , o presente artigo aborda as políticas culturais partidárias voltadas ao movimento, de modo a explicitar seu papel na construção de redes em nível nacional e internacional. Considerada um exemplo de compromisso revolucionário, a Nova Canção ocupou um lugar central no catálogo da gravadora DICAP, na programação da ONAE e nas páginas da revista Ramona veículos administrados pelas Juventudes Comunistas do Chile. Com isso, o Partido participou do próprio processo de definição da canção engajada chilena e ficou diretamente associado com este repertório. Compreender como se deu esta relação, ao invés de naturalizá-la, constituiu o objetivo primordial do estudo realizado.
\end{abstract}

\author{
Natália Ayo Schmiedecke \\ Doutora em História pela Universidade Estadual \\ Paulista Júlio de Mesquita Filho (UNESP). \\ Atualmente em Estágio Pós-Doutoral na \\ Universidade Estadual de Campinas (UNICAMP). \\ Campinas, São Paulo - Brasil \\ nati.ayo@gmail.com
}

Palavras-chave: Nova Canção Chilena. Partido Comunista

do Chile. DICAP. Ramona.

\section{Para citar este artigo:}

SCHMIEDECKE, Natália Ayo. "Ayudar a aquellos artistas que transformaron la canción en un arma de lucha": o papel das Juventudes Comunistas na difusão da Nova Canção Chilena (1968-1973). Tempo e Argumento, Florianópolis, v. 9, n. 22, p. 146 - 173, set./dez. 2017.

\section{DOI: $10.5965 / 2175180309222017146$}

http://dx.doi.org/10.5965/2175180309222017146

\footnotetext{
${ }^{1}$ Este texto apresenta resultados obtidos em minhas pesquisas de Mestrado e Doutorado (SCHMIEDECKE, 2015 e 2017) e parcialmente abordados em SCHMIEDECKE, 2014.
} 


\title{
The role of the Communist Youth in the diffusion of Chilean New Song (1968-1973)
}

\begin{abstract}
In a time marked by revolutionary expectation, many young supporters of socialism chose art as a privileged trench in the struggle for a new society. In the musical field, the 1960 s saw the emergence of the committed popular musician in Latin America, who began to use his work to take up a position facing contemporary political, social and economic issues. In Chile, the committed song found support in the Communist Party, which was the main responsible for the production and circulation of the repertoire linked to the Chilean New Song until the 1980 . Focusing on the period prior to the military coup of 1973, this article addresses the Party's cultural policies aimed at the movement, in order to make explicit their role in building national and international networks. Considered an example of revolutionary commitment, the New Song occupied a central place in the catalog of DICAP record label, as well as in ONAE programming and in the pages of Ramona magazine - vehicles run by the Communist Youth of Chile. With this, the Party participated in the very process of definition of the Chilean committed song and became directly associated with this repertoire. Understanding how this relationship occurred, instead of naturalizing it, was the primary objective of the performed study.
\end{abstract}

Keywords: Chilean New Song. Communist Party of Chile. DICAP. Ramona.

\section{Introdução}

A identificação da Nova Canção Chilena (NCCh) com a esquerda foi sempre ressaltada pela bibliografia, mas ainda são poucos os estudos voltados a examinar de maneira mais detalhada os vínculos existentes entre o movimento e as organizações políticas. No que se refere ao Partido Comunista (PC), embora a criação do selo Jota Jota (posteriormente DICAP), em 1968, seja considerada um marco na história do movimento, só recentemente alguns autores passaram a se deter sobre questões como o funcionamento da gravadora, seu catálogo e os interesses envolvidos no empreendimento. 
Dialogando com tais trabalhos, o presente artigo insere a DICAP no quadro das políticas culturais partidárias² de fins dos anos 1960 e início dos 1970 para demonstrar que o apoio dado ao movimento se deu em diferentes frentes e esteve relacionado a objetivos políticos e culturais mais amplos. Esta problemática será abordada enfocandose o desenvolvimento de um sistema de produção e circulação musical alternativo, que permitiu a formação de redes para a canção engajada.

Dado que a NCCh constitui um tema pouco visitado pela historiografia brasileira, o texto se inicia com a recuperação de algumas informações importantes acerca da conformação do movimento, colocando ênfase no engajamento político dos músicos. A seguir, examino as razões que levaram à criação da DICAP e a relação mantida pela empresa com a NCCh até 1973, sinalizando que, além de gravar e distribuir discos, a primeira atuou na organização de apresentações e turnês artísticas dentro e fora do Chile. Detendo-me sobre outro veículo do PC, a revista Ramona, dedico a última parte do artigo a identificar as estratégias de promoção do movimento levadas a cabo em suas páginas com vistas a conquistar o público jovem - que, conforme buscarei explicitar, constituiu o grande alvo das políticas culturais analisadas.

\section{A canção como arma}

Reunidas genericamente sob o rótulo de "Neofolklore", diferentes tendências musicais se propuseram a renovar o cancioneiro folclórico no Chile durante a década de 1960. Dentre elas, a fórmula cultivada por conjuntos como Los Cuatro Cuartos foi a que alcançou maior êxito comercial. Trata-se da versão chilena de grupos argentinos como Los Trovadores e Los Huanca Hua, que buscaram adaptar a canção folclórica ao público jovem urbano. Apresentando-se sempre com trajes formais (smoking), os conjuntos neofolklóricos chilenos tomavam como base ritmos tradicionais de diferentes regiões do

\footnotetext{
2 Trabalhos recentes vêm problematizando a limitação do conceito de "política cultural" às ações governamentais. Como argumenta a historiadora Mariana Villaça (2010, p. 24), "além da política cultural governamental, [existem] políticas culturais elaboradas no interior de instituições culturais [...] pelos agentes que neles operam e produzem, dessa forma, circuitos próprios de ação: micro-circuitos culturais". Nesse sentido, ainda que o PC tenha integrado a Unidade Popular, coalizão que governou o Chile entre 1970 e 1973, suas iniciativas no campo cultural seguiram uma linha própria que remonta às próprias origens do Partido, conforme análise realizada pela historiadora Carine Dalmás (2013).
} 
país para tematizar lugares, costumes e episódios históricos. Bastante estilizada, a interpretação tinha como marca um tipo de arranjo vocal que imitava as batidas do bombo leguero, originando o famoso "bomborombom".

Embora músicos como Patricio Manns e Rolando Alarcón estivessem próximos desta corrente em um primeiro momento, com o tempo suas composições passaram a adquirir contornos distintos, alinhando-se com outra vertente da música argentina: o Novo Cancioneiro. Defendendo o caráter dinâmico do folclore, este movimento - cujo manifesto foi publicado em 1963 - reivindicava a incorporação de temáticas contemporâneas e de novas formas estilísticas para aproximar a canção da problemática política e social (GARCIA, 2005).

Identificados com tal proposta, os irmãos Ángel e Isabel Parra fundaram a Peña de los Parra na capital chilena em 1965. Concebida como uma espécie de cooperativa de artistas, a Peña era uma casa noturna voltada para a juventude, na qual os cantores folclóricos podiam se apresentar e conversar com o público. Seu elenco original esteve composto por Ángel e Isabel Parra, Rolando Alarcón e Patricio Manns. Pouco depois, Víctor Jara juntou-se ao grupo.

O repertório cultivado por estes músicos estava conformado por canções que promoviam uma releitura do folclore, introduzindo temáticas e sonoridades que se afastavam das práticas tradicionais. Tendo em Atahualpa Yupanqui e Violeta Parra referenciais importantes, eles deram destaque à temática social e incorporaram gêneros oriundos de outros países latino-americanos - em especial, o repertório andino. A diferença com relação aos conjuntos neofolklóricos também se fez notar no âmbito interpretativo, pois além de trabalharem com outros tipos de arranjos, os músicos que se apresentavam na Peña não costumavam utilizar trajes especiais em suas apresentações.

Lançado ainda em 1965 pelo selo Demon, o LP La Peña de los Parra oferece um mostruário das canções que eram tocadas naquele ambiente. $\mathrm{O}$ disco reúne temas folclóricos de diversos lugares do continente, versões de canções compostas por músicos chilenos e estrangeiros e também composições dos próprios integrantes da Peña. Abrangendo uma variedade de gêneros musicais e instrumentos folclóricos da região e 
promovendo diálogos com compositores de países vizinhos, os músicos adotam uma perspectiva latino-americanista, que se explicita na faixa "Canto a mi América", uma composição do uruguaio Daniel Viglietti regravada por Ángel e Isabel Parra. A temática social também marca forte presença no LP, sendo representativa a canção "En Lota la noche es brava", de Patricio Manns. Interpretada somente com voz e violão e sem se filiar a nenhum gênero folclórico específico, ela denuncia as más condições de trabalho e o risco de vida permanente a que os mineradores da região de Lota se encontravam submetidos: "En Lota la noche es brava / para el que a la mina baja. / En Lota la noche acaba / con sangre en el mineral."

A Peña logo se tornou um modelo seguido em diferentes cidades chilenas, inclusive no meio universitário. Em meados de 1965, foi inaugurada a Peña de Valparaíso, ligada à Escola de Arquitetura da Universidade de Chile de Valparaíso e dirigida por Osvaldo "Gitano" Rodríguez e Gonzalo "Payo" Grondona. No ano seguinte, o Centro de Alunos da Escola de Artes e Ofícios da Universidade Técnica do Estado fundou a Peña de la UTE. Em sedes provinciais da UTE também foram formadas peñas, destacando-se as de Valdivia e Antofagasta.

Tais recintos se consolidaram não apenas como espaços de experimentação musical - nos quais os músicos podiam difundir canções que se adaptavam menos às regras da indústria fonográfica -, mas também como centro de reunião política da esquerda chilena. Referindo-se à Peña de los Parra, a bailarina Joan Jara indica que “Adquiriu a fama de viver cheia de revolucionários, desde marxistas até uma nova modalidade de cristãos de esquerda" (JARA, 1998, p. 141).

A articulação entre música, política e juventude se explicitou no movimento pela Reforma Universitária, iniciado em 1967. Naquele contexto, a música teve um papel importante não somente nas peñas universitárias, mas também nos atos, greves e ocupações realizados para pressionar a administração das instituições. A canção " "Móvil' Oil Special" foi composta por Víctor Jara em 1968 e se tornou uma espécie de hino da Reforma. Interpretada em ritmo de son cubano, a canção satiriza o modelo tradicional de universidade existente no Chile e relaciona o movimento reformista à luta anti- 
imperialista internacional: "Somos los reformistas, / los revolucionarios, / los antiimperialistas, / de la Universidad".

O movimento pela Reforma também deu projeção a conjuntos de música popular recém-formados - como é o caso de Tiemponuevo (surgido na Peña de Valparaíso em 1965), Quilapayún (formado em 1965) e Aparcoa (formado em 1966 por estudantes da Escola de Arquitetura da Universidade do Chile) - e estimulou o surgimento de outros, como o Inti-Illimani (fundado por estudantes da UTE em 1967). Como recorda Eduardo Carrasco, integrante do Quilapayún:

Gostávamos do ambiente carinhoso e sincero desta peña [da UTE]. Ali tivemos nossos primeiros êxitos verdadeiros, e ali também compreendemos que nossas ideias correspondiam a um espírito generalizado em quase todas as universidades chilenas. Nossas canções começaram a se fundir com a luta estudantil, e a refletir de um modo cada vez mais certo as aspirações de nossa geração. (CARRASCO, 2003, p. 57) $)^{3}$

Além de marcar o início da Reforma Universitária, 1967 também foi o ano em que os cantores engajados de diferentes partes do mundo se reuniram no Encuentro de la Canción Protesta, realizado em Havana. Segundo a cobertura realizada pela revista Casa de las Américas, "Nem todos [os participantes] estiveram de acordo com a denominação 'protesto', já que para alguns era muito limitada” (OSSORIO, 1967, p. 140). Entre as denominações alternativas sugeridas pelos músicos, encontravam-se "nova canção", “canção revolucionária”, “canção de conteúdo social” e “canção política revolucionária”. Nesse sentido, não teria havido acordo nas definições, "mas sim em relação aos fins que a canção de protesto persegue", os quais aparecem explicitados na "Resolução Final” do evento.

Fazendo referência ao "importante papel que cumprimos na luta de libertação dos povos contra o imperialismo norte-americano e o colonialismo", o documento postulava:

Os trabalhadores da canção de protesto devem ter consciência de que a canção, por sua particular natureza, possui uma enorme força de comunicação com as massas [...] Consequentemente, a canção deve ser

\footnotetext{
3 Todas as traduções de textos realizadas no presente artigo são de minha autoria.
} 
uma arma a serviço dos povos, não um produto de consumo utilizado pelo capitalismo para aliená-los. [...] A tarefa dos trabalhadores da canção de protesto deve se desenvolver a partir de uma tomada de posição definida junto ao seu povo frente aos problemas da sociedade em que vive. (apud OSSORIO, 1967, p. 140)

Seguindo este princípio, os signatários denunciaram os "crimes do imperialismo contra o povo do Vietnã", exigindo a retirada das tropas norte-americanas do país; manifestaram apoio ao movimento pelos direitos civis nos EUA; e exaltaram a Revolução Cubana, "que assinalou o verdadeiro caminho que devem tomar os povos da Ásia, África e América para libertarem-se" (p. 144). Assim, o anti-imperialismo foi tomado como bandeira comum a todos os povos que buscavam sua soberania, alimentando a expectativa de que a "revolução mundial” estava em marcha (GILMAN, 2003, p. 46).

As concepções defendidas no encontro - do qual participaram Rolando Alarcón, Isabel e Ángel Parra - exerceram influência sobre os músicos chilenos, estando fortemente presentes nos discursos que eles formularam acerca do papel "revolucionário" da arte e do artista. Em artigo escrito em 1967 para o jornal comunista El Siglo, por exemplo, Víctor Jara atribuía à canção de protesto os "valores essenciais do canto" e afirmava que ela seria "um fato, uma realidade e uma necessidade do homem contemporâneo", na medida que "Efetua uma verdadeira ação de limpeza do câncer que inculcaram ao povo os invasores. Fala-lhes da liberdade e daqueles que lutam em todo o mundo para alcançá-la”. Ao abordar temas como o imperialismo norte-americano, a Revolução Cubana, a Guerra do Vietnã e as condições de vida dos trabalhadores latinoamericanos, denunciando os “opressores" e posicionando-se ao lado dos "oprimidos”, “A canção de protesto destrói [...] esta ação alienante do capitalismo e é por isso que cumpre um papel importantíssimo na reivindicação do homem", comunicando massivamente o trabalho dos combatentes "que guiam os povos à sua libertação" (JARA, 1970, p. 11).

Conforme constatou o historiador Caio Gomes (2015, p. 103) ao analisar os casos de Rolando Alarcón e Ángel Parra, o impacto do Encuentro também se fez notar na discografia dos músicos chilenos, “impulsionando uma radicalização dos 
posicionamentos políticos, uma explicitação da convocação à ação, uma presença marcante do anti-imperialismo e um fortalecimento do discurso latino-americanista".

Levando à prática o princípio de que cabia ao artista revolucionário posicionar-se politicamente, Víctor Jara, Isabel e Ángel Parra, Rolando Alarcón, Patricio Manns, Osvaldo Rodríguez, Sergio Ortega e os conjuntos Quilapayún, Inti-Illimani, Aparcoa e Tiemponuevo, entre outros, participaram ativamente da campanha presidencial de 1970, apoiando o candidato da Unidade Popular (UP)4, Salvador Allende. Sob o lema "Não há revolução sem canções", eles se apresentaram em comícios da UP e gravaram canções que tematizavam a conjuntura eleitoral - como "En septiembre canta el gallo", de Isabel Parra; “Unidad Popular”, de Ángel Parra; e “Venceremos”, marcha composta por Sergio Ortega e interpretada pelo Quilapayún (ROLLE, 2000, p. 12-13).

Intitulado Via chilena ao socialismo, o programa de governo da UP se propunha a implementar o socialismo no país pela via "pacífica” (ou não armada), respeitando a institucionalidade democrática. Allende venceu as eleições em 4 de setembro de 1970, tomou posse dois meses depois e governou o Chile até 11 de setembro de 1973, quando foi derrubado pelo golpe militar que conduziu à ditadura de Augusto Pinochet.

No contexto da campanha e do governo da UP, a Nova Canção Chilena se consolidou como um movimento musical. O termo foi utilizado pela primeira vez pelo radialista Ricardo García no festival homônimo realizado em 1969, cuja programação era bastante heterogênea, mas acabou ficando identificado com os músicos que se engajaram no projeto da Via chilena ao socialismo. O apoio dado ao governo em diversos eventos políticos, discos, canções e declarações à imprensa valeu-lhes uma imagem de “arte oficial”, embora, na prática, eles não tenham contado com formas especiais de patrocínio estatal nem tenham participado substancialmente das políticas culturais oficiais. Ao contrário, a maioria dos músicos sequer conseguiu profissionalizar-se no período.

\footnotetext{
${ }^{4}$ A Unidade Popular foi criada em 1969 através de uma aliança de três grandes partidos - Comunista, Socialista e Radical - e três organizações menores - Partido Social Democrata, Ação Popular Independente e Movimento de Ação Popular Unificado. Em 1971, o Partido de Esquerda Radical e o Movimento de Esquerda Cristã se incorporaram à coalizão, mas o primeiro se desligou no ano seguinte.
} 
Mas se o movimento não contou com o apoio expresso do governo como um todo, não podemos dizer o mesmo com relação ao PC, que foi o partido integrante da UP mais atuante na esfera artística. É importante mencionar que, historicamente, o PC ocupou um lugar de destaque no cenário cultural nacional, tendo impulsionado diversas manifestações artísticas desde suas origens. Luis Emilio Recabarren, fundador do

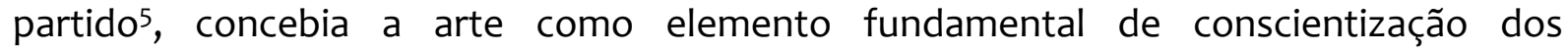
trabalhadores, demonstrando especial interesse pelo teatro e pela poesia. Nos anos 1930 e 1940, no contexto do movimento antifascista internacional e do governo da Frente Popular no Chile, diversos artistas e escritores se filiaram ao PC, com destaque para o poeta Pablo Neruda (DALMÁS, 2012). Tal influxo foi crescendo nas décadas seguintes e é possível falar em uma hegemonia do partido no campo cultural em fins dos anos 1960 (PADILLA, 2015).

Sem fugir à regra, grande parte dos músicos da NCCh eram filiados ou simpatizantes do PC. Dentre eles, Víctor Jara, Eduardo Carrasco e Isabel Parra representam casos especiais, pois integravam o Comitê Central das Juventudes Comunistas (la Jota), a ala jovem do partido - o que ajuda a explicar o respaldo dado por esta instituição ao movimento. Como veremos a seguir, a Jota lançou mão de diferentes recursos para promover a canção engajada ${ }^{6}$ entre 1968 e 1973, configurando-se na principal impulsionadora da NCCh em nível nacional e internacional.

${ }^{5}$ Luis Emilio Recabarren fundou o Partido Obreiro Socialista em 1912, o qual converteu-se em Partido Comunista do Chile em 1922.

${ }^{6}$ Conforme observou o historiador Marcos Napolitano (2011, p. 27), o termo arte engajada "causa muita confusão conceitual e suscita juízos de valor a priori, contra ou a favor" e "O próprio estatuto de "artista engajado' (em última instância, de 'intelectual engajado') tem sido objeto de muita discussão, não apenas acadêmica, mas também política". No âmbito acadêmico, observa-se a predominância da tradição francesa nos debates sobre o conceito de engajamento. Fortemente influenciada pelas proposições do filósofo Jean-Paul Sartre, a escola francesa "tende a plasmar o conceito moderno de 'intelectual' à própria ideia de engajamento, à medida que o intelectual é definido como aquele que coloca sua palavra 'lítero-jornalística' a serviço de causas humanistas, republicanas e progressistas". Esta ênfase na palavra escrita como instrumento característico de intervenção ou identidade intelectual tem sido relativizada por um número crescente de trabalhos dedicados a examinar as relações estabelecidas entre movimentos artísticos e regimes políticos. No caso dos anos 1960 e 1970 latino-americanos, tal deslocamento se mostra especialmente importante, já que com as "mudanças estruturais [ocorridas] no campo artístico-cultural como um todo [...] o conceito de engajamento, tal como delimitado por Sartre [...] sofreu no Brasil (e em outros países, sobretudo da América Latina) uma releitura [...] Ao contrário do que defendia o filósofo francês, o espaço de atuação privilegiado do artista/intelectual não foi a 


\section{DICAP e ONAE}

Em 1968, foi realizado na Bulgária o IX Festival Mundial das Juventudes e dos Estudantes pela Solidariedade, a Paz e a Amizade - dedicado à solidariedade com os vietnamitas durante a Guerra do Vietnã. Para eleger representantes nacionais do festival, o jornal El Siglo de Santiago organizou uma campanha e encarregou a Jota de editar um disco que demonstrasse a "inquietude" da juventude chilena com as questões colocadas pelo evento. O LP gravado foi $X$ Viet-nam, do conjunto Quilapayún, cuja faixa-título bradava: “Las águilas negras / rompen sus garras / contra el heroico pueblo en Vietnam. / [...] / Yankee, yankee, yankee, / cuidado, cuidado, / águila negra, ya caerás / el guerrillero te vencerá". De acordo com Eduardo Carrasco (2003, p. 131), "A iniciativa deu suas provas, e a direção das Juventudes Comunistas concordou em formar um pequeno selo de discos para continuar difundindo música com conteúdo revolucionário".

Ainda em 1968, o selo lançou a obra coletiva X la CUT, em apoio à Central Única de Trabalhadores do Chile. O empreendimento teve continuidade, passando a abranger também discos em formato single, e a partir de meados de 1970 o nome Jota Jota foi substituído por DICAP (Discoteca del Cantar Popular). ${ }^{7}$ O crescimento $^{8}$ da gravadora foi potencializado pelo grande envolvimento dos artistas com o projeto, o que permitiu o desenvolvimento de um modo de trabalho coletivo, em conformidade com o ideário comunista. Para escoar a produção, fez-se necessário criar um sistema alternativo de distribuição. No princípio, foram os próprios militantes do partido que, contando com apoio de sindicatos e grupos universitários, divulgaram e venderam os discos pessoalmente. As primeiras remessas comerciais foram feitas a livrarias e, aos poucos, as casas de discos passaram a fazer encomendas.

prosa ou o ensaio [...] mas as artes que apelavam aos sentidos corpóreos, através de imagens, sons e ritmos" (NAPOLITANO, 2001, p. 104).

7 Nem X Viet-nam, nem X la CUT apresentavam informações sobre a empresa gravadora. A partir do LP seguinte, Pongo en tus manos abiertas... (Víctor Jara, 1969), todos passaram a constar como produzidos e distribuídos pela gravadora DICAP. Em 1969, foi criado o selo DICAP, indicado pela primeira vez no LP Danai canta a Neruda (1969), da cantora grega Istros Danai, ainda sem o logotipo da empresa, que seria oficializado no ano seguinte. Os dois selos coexistiram no catálogo da gravadora por alguns meses, mas ainda em 1970 o Jota Jota foi extinto (SCHMIEDECKE, 2014, p. 202).

${ }^{8}$ Este crescimento pode ser percebido em uma tabela elaborada pela historiadora Jan Fairley (1977, p. 123) que registra a quantidade de discos prensados pela gravadora entre 1968 e 1973, indicando também o número de títulos lançados e relançados em cada ano. 
A análise do catálogo da gravadora no período anterior ao golpe de 1973 aponta para uma crescente diversificação de seu repertório: se em um primeiro momento foram privilegiadas as canções de temática política explícita, o trabalho conjunto entre produtores e músicos estimulou a busca por novos conteúdos, o que foi viabilizado pela profissionalização da empresa. Conforme destacou o musicólogo Gustavo Miranda (2012, p. 98), "isso significava desvincular-se - na forma e não no fundo - da figura das Juventudes Comunistas", processo que ficaria evidenciado em três mudanças ocorridas já nos primeiros anos: além da já mencionada alteração de nome para DICAP, sua sede saiu do Comitê Central da Jota e Eduardo Carrasco, militante comunista, foi substituído na direção artística por Juan Carvajal, que fora contratado com o fim de proporcionar maior objetividade às produções ali realizadas

A partir de então, os gestores procuraram traçar o perfil da empresa. De acordo com Carvajal, três seriam seus objetivos principais, subdivididos em objetivo artístico, objetivo econômico e objetivo político. No que tange ao primeiro aspecto, a DICAP buscaria "resgatar as formas musicais populares e cultas em primeiro lugar chilenas e latino-americanas"; difundir a "música revolucionária internacional” bem como "toda a música assegurada do ponto de vista de sua qualidade que tenha ou possa ter uma difusão popular ou um conteúdo popular"; e contribuir com "o surgimento de uma Cultura Nacional e proletária" (CARVAJAL, 1972, p. 7).

O objetivo econômico fundamental seria "financiar as incumbências específicas da DICAP e com isso possibilitar seu crescimento e desenvolvimento". Por fim, os objetivos políticos seriam quatro:

\footnotetext{
Ajudar aqueles artistas que transformaram a canção em uma arma de luta, difundindo canções especialmente entre os meios proletários e estudantis [...] Nuclear em torno da DICAP uma grande quantidade de artistas [...], orientando seu trabalho à política cultural do partido e do Governo Popular [...] Vínculo e aproximação cultural nos países socialistas [e] Levar a música chilena ao exterior, dando a conhecer a política revolucionária do partido e do Governo Popular. (p. 7)
}

Portanto, a DICAP procurou ser reconhecida pelo valor cultural e político de seu trabalho. Por um lado, atribuiu a si a missão de contribuir com o desenvolvimento de uma 
“nova cultura", primando pelo aspecto estético das obras, "resgatando" conteúdos considerados revolucionários e difundindo-os entre os trabalhadores, tidos como protagonistas da almejada revolução. Por outro, dedicou-se à propaganda interna e externa do governo da UP e ao reforço do vínculo com Cuba e a União Soviética - cujo apoio era fundamental no contexto da Guerra Fria.

A julgar pelo catálogo da gravadora, pelas estratégias de publicidade utilizadas e pelas declarações de seus representantes, a identificação com a NCCh foi considerada estratégica para alcançar tais objetivos. O movimento responde por 48 dos 66 LPs lançados pela DICAP entre 1968 e 1973 e seus anúncios publicitários apresentavam-na como "vanguarda da Nova Canção Chilena" - ideia que foi reiterada em diversas ocasiões pelo diretor Juan Carvajal e pelo coordenador-geral Hernán Briones.

Em entrevista para a revista El Musiquero, Briones afirmou que "A DICAP nasce como um aparato que centraliza, coordena e faz extensivo este aporte dos artistas revolucionários" (OLIVARES, 1971, p. 2), remetendo à NCCh, conforme explicita Carvajal: “A DICAP pretende centralizar o movimento da Nova Canção Chilena” (OLIVARES, 1971, p. 2). A preferência pelo repertório ligado ao movimento se justificaria porque "queremos que o povo tome consciência" (p. 4). Tanto nesta matéria como em outra publicada no mesmo período na revista Ahora, Carvajal alegava que antes da criação da DICAP as canções de conteúdo político e social não encontravam espaço na indústria fonográfica nacional, de modo que "A função da DICAP foi servir como catalizador, reunir os artistas, ajudá-los a aportar um caminho de saída - praticamente o único - para a Nova Canção", constituindo-se no "lugar de convergência da nova música” (DICAP, 1971, p. 43).

É preciso relativizar a ideia segundo a qual a DICAP nasceu com o objetivo claro de incentivar o desenvolvimento da NCCh, que não conseguiria espaço nas gravadoras existentes até então. Na realidade, uma parcela significativa dos discos lançados por tais músicos antes e depois da criação da DICAP foi produzida pelas majors atuantes no país (em especial, a EMI Odeon) ou por companhias nacionais não identificadas com a esquerda política (como Arena/Demon). Se considerarmos apenas os LPs, podemos estimar em 40\% os discos da NCCh produzidos pela DICAP (SCHMIEDECKE, 2017, p. 260261). 
Destarte, a sua criação não representou a "salvação" de músicos relegados ao anonimato. Mas, ao garantir a circulação de repertórios mais politizados, ela estimulou o desenvolvimento de um tipo de canção que encontrava dificuldades em ser aceito pela indústria fonográfica. Isso não quer dizer que a temática política e social estivesse banida dos discos produzidos por outros selos e nem que a DICAP gravasse apenas esse tipo de repertório. O ponto que quero destacar é que, a partir de 1968, os músicos que viriam a integrar a NCCh puderam satisfazer, através das gravadoras existentes, as diferentes “faces” de sua criação musical. Esta percepção é reforçada se observamos que Víctor Jara, Quilapayún e Inti-Illimani continuaram a lançar discos pela EMI Odeon durante todo o período enfocado, ao mesmo tempo em que produziam outros pela DICAP.

O interesse em cooptar o movimento - visível nas declarações de Carvajal - se deve à percepção de que ele havia se transformado "em uma verdadeira frente de luta ideológica que tem dado duros golpes no inimigo, roubando-lhe influência no campo juvenil", conforme um trecho do informe apresentado pela Comissão Nacional de Cultura da Jota na Assembleia Nacional de Trabalhadores da Cultura do PC, realizada em 1971 (PARTIDO COMUNISTA DE CHILE, 1971, p. 74). No mesmo sentido, Gladys Marín - que era membro da Comissão Política do PC e Secretária Geral da Jota - havia manifestado dois anos antes que o trabalho da gravadora, assim como as demais iniciativas culturais da organização, era concebido como uma maneira de inserir a juventude na luta dos trabalhadores: "Junto ao combate nas ruas, à greve de protesto, está o selo Jota-Jota, os artistas juvenis, suas canções de protesto" (PARTIDO COMUNISTA DE CHILE, 1969, p. 70).

O documento de 1971 esclarece que não se tratava de instrumentalizar a arte, mas de "ajudar os artistas que transformaram a canção em uma arma de luta", assegurando sua liberdade criativa (PARTIDO COMUNISTA DE CHILE, 1971, p. 76). ${ }^{9}$ Outro objetivo político seria levar esse repertório ao exterior, ajudando a "formar a nova imagem do Chile”. Daí as diversas turnês organizadas pela Jota entre 1970 e 1973, em que músicos

9 Embora os representantes da DICAP insistissem que o selo não realizava qualquer tipo de censura, Eduardo Carrasco (2003, p. 129) descreve problemas enfrentados pelo Quilapayún para incluir uma homenagem a Che Guevara em um disco - questão que acabou sendo levada ao Secretário-Geral do PC, Luis Corvalán, que por fim emitiu um parecer favorável. Tal episódio deixa antever que, assim como as demais gravadoras, a DICAP operava seleções de acordo com suas possibilidades e interesses, fossem eles de ordem econômica ou política. 
filiados ao partido atuavam em diferentes países. No início do governo da UP, por exemplo, Quilapayún e Isabel Parra permaneceram seis meses fora do Chile, realizando um total de aproximadamente 130 apresentações na Hungria, Romênia, União Soviética, França, Suécia, Dinamarca, Suíça, Áustria, Alemanha (Oriental e Ocidental), Inglaterra e Cuba. Conforme a análise realizada pelo historiador Javier Rodríguez (2016, p. 75), tal turnê possibilitou a criação de "redes artísticas, culturais e comerciais que terão efeitos a longo prazo, na medida que a intensificação da circulação desses músicos cimentará o caminho para o resto dos artistas chilenos", além de ter sido encarada como "uma oportunidade para mostrar o que ocorria no Chile sob o marco da chamada operação verdade, que consistia tanto em desmentir os juízos contrários ao governo de Salvador Allende [...] como em apresentar o rosto real da revolução chilena".

A fim de impulsionar as ações neste campo, foi criada em 1971 a Organização Nacional do Espetáculo (ONAE), uma iniciativa da DICAP que tinha como incumbência específica organizar apresentações artísticas. De acordo com uma nota publicada na revista Ramona, o grande objetivo da ONAE seria "colaborar com o desenvolvimento artístico popular", ao mesmo tempo em que "Também possibilita a vinda de artistas estrangeiros e a saída dos nossos" (PANORAMA, 1972b, p. 7).

Segundo o musicólogo Alfonso Padilla (2015), a criação da agência foi motivada pela crescente demanda de participação dos músicos da NCCh em eventos culturais e políticos. Em entrevista para a revista Onda, Juan Carvajal afirmou que o fator decisivo era de ordem econômica, pois "até esse momento, tudo o que fosse organização de espetáculos estava em mãos de particulares, que na maioria dos casos terminavam dando calote nos artistas. Conosco a coisa é distinta. O artista encontra desde o começo um trato digno" (AGUILERA, 1973, p. 32). Assim, os músicos ficariam com a maior parte do dinheiro arrecadado com a venda de ingressos de suas apresentações, diferentemente do que ocorria com o comércio de discos.

Dentro do Chile, o empreendimento da ONAE de maior destaque foi uma série de ciclos de recitais promovidos entre 1972 e 1973. O primeiro que aparece comentado nas fontes consultadas teve lugar no Teatro Gran Palace de Santiago e foi inaugurado por Charo Cofré e Tito Fernández, alcançando grande sucesso de público - o que se repetiria 
na apresentação do conjunto Quilapayún ocorrida no dia seguinte (ONAE, 1972, p. 5). Alguns meses depois, um novo ciclo teve início, desta vez no imponente edifício Gabriela Mistral, que havia sido construído para sediar a terceira edição da Conferência das Nações Unidas sobre Comércio e Desenvolvimento (UNCTAD III), em 1972. O primeiro recital reuniu Roberto Parra e Tito Fernández e as apresentações seguintes ficaram a cargo de Inti-Illimani, Quilapayún e Illapu. "Mas a ONAE não só se limita a apresentar recitais em lugares como o Gran Palace ou a ex-UNCTAD. Mantém um trabalho permanente com sindicatos através de todo o país", como Carvajal fez questão de esclarecer. Ainda de acordo com o diretor, intencionava-se expandir o repertório para além da NCCh: "A ideia é poder apresentar também recitais com cantores populares do gênero internacional [...] e também preparar outro ciclo com os mais 'cebolleros'10 e que são os que têm o maior impacto entre o público [...]" (AGUILERA, 1973, p. 32).

Além de organizar turnês dos músicos da NCCh por diferentes países europeus e latino-americanos, a DICAP promoveu a circulação internacional de seus discos. Segundo Carvajal, as produções do selo "têm percorrido o mundo inteiro", o que estaria sendo conseguido na Europa “em grande medida com as embaixadas artísticas de nosso país" (CARVAJAL, 1972, p. 7). A título de exemplo, ele menciona obras do Quilapayún e IntiIllimani já gravadas na França. Na mesma linha, uma matéria publicada em agosto de 1972 na revista Ramona comentava a respeito da edição, na Argentina, do LP Santa María de Iquique (Quilapayún); e, na Venezuela, de Autores Chilenos (Inti-Illimani), El derecho de vivir en paz (Víctor Jara), Folklore andino (Curacas), Basta (Quilapayún), Canciones funcionales (Ángel Parra) e Recopilación de cantos inéditos de Violeta (Isabel Parra) (PANORAMA, 1972a, p. 7).

A NCCh também foi encarada pelo PC como um meio de alcançar objetivos culturais. O informe da Jota apresentado na assembleia de 1971 afirmava que uma das metas principais da DICAP seria participar ativamente da renovação da música folclórica e popular (PARTIDO COMUNISTA DE CHILE, 1971, p. 76). Compartilhando da concepção de que o folclore possuía um caráter dinâmico, o informe do Coordenador de Folcloristas apresentado na mesma assembleia postulava que somente os artistas populares -

\footnotetext{
10 Termo utilizado para remeter à música "que faz chorar" - em especial, às baladas românticas.
} 
provenientes do "seio das massas" - poderiam recriá-lo. Para tanto, seria necessário realizar uma seleção, dado que "nem todas as manifestações folclóricas correspondem aos interesses revolucionários" (PARTIDO COMUNISTA DE CHILE, 1971, p. 93). A NCCh seria um exemplo de como operar esta seleção de maneira revolucionária; portanto, estaria indicando o caminho a ser tomado pelos artistas populares. Daí a importância de que o PC, através da DICAP, continuasse a apoiar o movimento.

Ao identificar diretamente os interesses deste último com os do partido, postulando que a NCCh se definiria por seu comprometimento com a causa revolucionária, as propagandas e discursos sobre a DICAP desconsideraram a diversidade do repertório abarcado sob o nome Nova Canção Chilena. Mas esta diversidade apareceu representada no catálogo da gravadora, que não se limitou ao conteúdo político explícito, em conformidade com as propostas de conquistar o público jovem e de contribuir com a renovação da música de inspiração folclórica. O LP Cantando por amor (1969), de Isabel Parra, por exemplo, é composto por treze faixas que abrangem em igual proporção temas amorosos e canções de crítica social, sem entrar na problemática política. A instrumentação utilizada nas faixas inclui violão, flauta, violino, acordeão e charango e os gêneros musicais abrangidos são sirilla, polca, canto a lo humano, cueca, decima e mazurca.

Por sua vez, o LP Música andina, (1972), do conjunto Illapu, contém cinco faixas instrumentais e cinco canções de temática folclórica ou social. Nas liner notes incluídas na contracapa do álbum, o conjunto Inti-Illimani menciona "Sua clara visão, que desconhece fronteiras entre nossos países", "o virtuosismo de seus temas instrumentais" e o fato de os integrantes do Illapu serem "Possuidores de uma sólida base de saber folklórico". De acordo com uma nota publicada na revista Onda, "Ao lançá-los ao disco, o selo DICAP fez com que fossem apadrinhados pelo Inti-Illimani”, que àquela altura já era um grupo consagrado da NCCh. Aqui explicita-se o papel da gravadora na construção de vínculos entre os músicos.

Também é importante reforçar que nem todo o catálogo da DICAP se destinava ao movimento, como demonstram os LPs Blops (1970), do conjunto de rock chileno homônimo; e Tangos en el Puerto (1972), do grupo argentino Fabián Rey y Trío. Este 
último disco constitui um dos únicos dez LPs de intérpretes estrangeiros presente no catálogo da gravadora, cuja ênfase estava posta no repertório nacional.

Embora não existam dados sobre as vendas realizadas pela DICAP no período estudado - o que se deve à destruição de sua sede durante o golpe militar -, um artigo publicado na revista El Musiquero em meados de 1971 sinaliza que ela conseguiu se inserir com sucesso em um segmento do mercado juvenil:

Este selo gravador tem ganhado paulatinamente terreno graças a vários fatores. A alta venda que alcançam os discos editados que são absorvidos por um mercado juvenil que vai aumentando. As universidades, as escolas e especialmente os setores da juventude que escapam da onda beat, ou que pelo menos se sentem identificados através das temáticas das canções. (OLIVARES, 1971, p. 5)

\section{Ramona}

No âmbito da imprensa, a disputa do PC pelo público jovem seria travada por meio da revista Ramona, que circulou semanalmente de 29 de setembro de 1971 a 11 de setembro de 1973. Como explica a historiadora Carine Dalmás, da mesma forma que as brigadas muralistas ${ }^{11}$ da Jota, o nome da revista constitui uma homenagem à militante comunista Ramona Parra, morta por forças policiais aos dezenove anos de idade no dia 16 de janeiro de 1946, durante uma manifestação trabalhista. Tomada como exemplo de jovem revolucionária, ela se converteu na primeira "mártir" da Jota, sendo valorizada por sua entrega total à luta dos trabalhadores (DALMÁS, 2006, p. 67-68).

\footnotetext{
${ }^{11}$ Segundo Carine Dalmás (2006), as Brigadas Ramona Parra (BRP) foram organizadas pelas Juventudes Comunistas do Chile em 1969 e oficializadas como órgãos de propaganda do Partido no ano seguinte. Seus planos de trabalho podem ser divididos em dois momentos: durante a campanha eleitoral, percorreram o país gravando as consignas da UP em rochas, paredes, muros, pontes e outras superfícies; após a vitória de Allende, direcionaram suas ações para defendê-lo. Dalmás afirma que era o Comitê Central do PC quem definia o conteúdo das mensagens veiculadas pelas brigadas, mas a produção dos murais se dava de forma coletiva, envolvendo artistas com ou sem filiação partidária e estimulando a participação popular - aspecto "fundamental para um projeto cultural que visava educar, socializar e integrar as pessoas sobre as transformações políticas" ( $p .71)$, contribuindo também para democratizar as artes plásticas. Valorizadas nacionalmente por seu papel político-cultural, as BRP ficaram identificadas como expressão visual do governo de Allende e seus símbolos e traços característicos foram utilizados para ilustrar capas de discos e cenários de palcos em que se apresentaram músicos da NCCh. Alguns destes, por sua vez, compuseram canções em homenagem aos brigadistas, destacando-se a canção "Las B.R.P." (1973), de Ángel Parra, e a marcha "B.R.P." (1970), de Víctor Jara.
} 
Tal representação estava afinada com as resoluções do XIV Congresso do PC (1969) para a juventude, sintetizadas no informe de Gladys Marín. Reconhecendo o proletariado como vanguarda do processo revolucionário, o texto acusava o “imperialismo" de tentar distanciar a juventude da luta política:

O que se pretende é afastar a juventude da luta de classes, levantá-la como elemento autônomo na sociedade, enfrentá-la com a geração anterior [...] Alguns agarram esta musiquinha e não se dão conta de que à luta social não se chega por quantidade de anos ou por reações hormonais, senão por localização social ou de consciência. (PARTIDO COMUNISTA DE CHILE, 1969, p. 68-69)

A recusa do conceito de juventude difundido pela grande mídia se relacionava à intenção de canalizar a "rebeldia juvenil" para o combate ao sistema capitalista. Como observa Dalmás (2006, p. 68), se a juventude era valorizada por sua dinâmica, "ela precisava ser educada e dirigida pelo Partido para lutar junto a todos os segmentos sociais nos movimentos de massas". Em conformidade com esta concepção, as atividades culturais da Jota são apontadas por Marín como meio de inserção dos jovens na luta dos trabalhadores através de "formas próprias, em especial, aquelas que recolhem seu sentir e inquietude" (PARTIDO COMUNISTA DE CHILE, 1969, p. 70).

Buscando constituir uma dessas “formas próprias”, Ramona era editada pela Sociedade Impressora Horizonte, impressa nas oficinas da Editora Nacional Quimantú12 e publicada inicialmente às sextas-feiras e posteriormente às terças, totalizando 98 números. ${ }^{13}$ A revista abordava temas variados, com destaque para: política nacional, política internacional, instituições de ensino (com ênfase no movimento estudantil de

${ }^{12}$ No início de 1971, a Editorial Zig Zag foi estatizada, convertendo-se na Editora Nacional Quimantú. A partir do ano seguinte, definiu-se um novo perfil editorial e a lógica econômica foi sendo reajustada por uma política cultural voltada à massificação da informação. Após o golpe militar de 1973, a editora foi fechada.

${ }^{13}$ A primeira equipe editorial de Ramona era integrada por Carlos Berger (diretor), Camilo Taufic (diretoreditor), Manuel Contreras (subdiretor) e Carlos Osorio (representante legal). No número 53, esses cargos passaram a ser ocupados por Marcel Garcés (diretor), Sergio Muñoz Riveros (subdiretor), José Gay (chefe de redação, substituído por Guillermo Tejada no n. 75) e Elías Azevedo (representante legal). Novas mudanças aconteceram no número 92, quando Sergio Muñoz Riveros se tornou diretor; Guillermo Tejada, subdiretor; e Roberto Careaga, chefe de redação. Na penúltima edição, Francisco Cataldo Araya assumiu a direção e novos editores foram incorporados, especializando-se em determinados assuntos. Desse modo, a ficha técnica passou a indicar como editores Roberto Careaga (atualidade nacional), Claudia Lanzarotti (cultura e espetáculos), Eduardo Bruno (esportes), Ligia Flores (moda, artesanato e lazer), Vivian Barry (crônica) e Felipe de la Parra (frente de massas). 
escolas e universidades) e relacionamentos (sexo, casamento etc.). Também estão presentes em todas as edições matérias sobre esportes, expressões artísticas e moda. Outros assuntos frequentemente tratados eram drogas, trabalhos voluntários, curiosidades históricas, viagens e palavras cruzadas.

Embora a ênfase estivesse posta no conteúdo político, Ramona procurou mesclá-lo com o entretenimento, "suavizando" as mensagens ideológicas ao mesmo tempo em que politizava o que era considerado "fútil". Isso significa que a revista não seguia de maneira ortodoxa as diretrizes do Partido; ao contrário, ela se mostrou relativamente aberta a conteúdos pouco identificados com a noção de juventude revolucionária, como é o caso do programa Música Libre ${ }^{14}$, ao qual dedicou matérias simpáticas.

A convivência, na publicação, entre cultura política comunista e cultura jovem convencional pode ser percebida observando-se os pôsteres publicados a partir do número 17, os quais abarcaram desde Luis Emilio Recabarren até a Miss Mechona FECH de $1972^{15}$ - passando por Marx, Lênin, Angela Davis, Clint Eastwood, jogadores de futebol e integrantes da NCCh. Não obstante tal variedade, é perceptível a preferência da revista por personalidades chilenas e estrangeiras que apoiavam o governo da UP ou outros movimentos considerados revolucionários - caso do jogador de futebol Carlos Caszely e dos músicos Isabel Parra, Charo Cofré, Osvaldo Rodríguez, Willy Oddó (membro do Quilapayún), Dean Reed, Joan Manuel Serrat, Daniel Viglietti e Peter Yarrow, entre outros.

O posicionamento de Ramona frente ao tema dos ídolos juvenis aparece sintetizado na oitava edição, na seção “Las respuestas de Manuel”, dedicada a esclarecer algumas dúvidas de leitores sobre questões diversas. Um deles perguntou sobre "a necessidade de que se ressaltem ou não determinadas pessoas, cantores, políticos, etc., como ídolos juvenis", pois enquanto "alguns pensam que é nocivo que à juventude lhe

\footnotetext{
14 Programa televisivo exibido de segunda a sexta-feira no Canal 7. Conduzido inicialmente por Ricardo García e posteriormente por César Antonio Santis, consistia em uma série de videoclipes em que jovens atores dançavam os hits musicais do momento, com coreografias elaboradas por Pepe Gallinato. Como explica o historiador Cesar Albornoz (2014, p. 167), “Música Libre era um programa consular. Era a construção virtual de uma juventude idílica, descongestionada e alienada da contradição. [...] Era em todo aspecto contrarrevolucionário. Mas para a juventude chilena era um de seus preferidos".

15 Miss Mechona era o título atribuído anualmente à caloura eleita mais bonita pela Federação de Estudantes da Universidade do Chile (FECH).
} 
pintem determinados ídolos, outros pelo contrário acreditam que os ídolos são uma necessidade da juventude" (LAS RESPUESTAS..., 1971, p. 34). Em sua resposta, o autor da coluna explicou:

Afirmamos que os ídolos são uma necessidade psicológica e social dos jovens e dos povos [...] por tudo o que representa sua personalidade ideal. Qual é o perigo de determinados ídolos?; que representem valores, formas de vida e êxito individualistas, levando à juventude formas de vida e pensamentos negativos. [...] Nesse sentido estamos contra estes ídolos. Mas não contra aqueles que simbolizam em si as características de um povo em luta, as características de honestidade, de sacrifício, de arrojo pessoal [...] mas também de beleza, de pureza, etc. Como ficar por exemplo contra esse ídolo de massas que é Fidel Castro, como foi em seu tempo Luis Emilio Recabarren, como em outro plano são os Quilapayún, etc. [...] [?] (p. 34)

A inclusão do conjunto Quilapayún na lista de “ídolos positivos" permite compreender a ênfase dada por Ramona ao movimento da NCCh. As diversas entrevistas realizadas com os músicos tinham como temas principais suas trajetórias artísticas, discos recém-lançados e participações em festivais da canção ou eventos políticos. Também eram recorrentes matérias que realizavam coberturas de suas turnês, afirmando que os conjuntos e solistas estariam triunfando no exterior. Ficava sugerido, assim, que o motivo da participação tímida do movimento nos rankings de popularidade nacionais seria o pouco espaço dado pelos meios de comunicação ao seu repertório.

Algumas das seções da revista especificamente dedicadas à música procuraram contornar tal situação, dando visibilidade ao trabalho daqueles artistas, enquanto outras se detiveram sobre os hits do momento. No primeiro caso, encontram-se "Prenda la oreja”, "Panorama” e “¡A cantar todos!”. Já as seções focadas nos hits eram: "El ranking de Ricardo García”, “Panorama” (novamente), "Superventas” e “Disco notas”.

“El ranking de Ricardo García” foi publicado entre os números 1 e 27 nas páginas iniciais da revista. A coluna listava as canções e os discos (nacionais e internacionais) mais vendidos da semana. Fora dela, García assinou diversos artigos sobre música de diferentes estilos e também foi o responsável por elaborar os balanços anuais da produção discográfica, informando sobre as preferências do público. 
Já “Prenda la oreja”, publicada entre os números 1 e 26, era assinada pelo locutor radial Agustín “Cucho" Fernández e apresentava comentários sobre solistas e conjuntos, geralmente abordando seus últimos lançamentos e suas participações em eventos. Os comentários eram sucintos e a linguagem empregada era bastante coloquial, procurando aproximar-se do público jovem. Abrangendo diversos gêneros musicais nacionais e internacionais, a coluna reservava bastante espaço à NCCh, abordada de maneira elogiosa ou meramente informativa. A simpatia por este repertório pode ser percebida na décima edição, em que Fernández realizou um balanço de 1971 (p. 50), listando como melhores do ano Quilapayún (melhor disco single), Tito Fernández (melhor álbum nacional), Luis Advis (melhor arranjador), Víctor Jara (melhor disco folclórico e melhor cantor folclórico) e Los Moros (melhor grupo folclórico). Deste modo, representantes da NCCh foram considerados os melhores em todos os quesitos possíveis, pois os demais diziam respeito à produção internacional e à música erudita.

No número 28, foi criada a seção "Panorama”, que apresentava um quadro geral dos acontecimentos artísticos ocorridos dentro e fora do Chile. A música geralmente era abordada na subseção "Discos”, que reunia as extintas “El ranking de Ricardo García” e "Prenda la oreja" - ou seja, abarcava tanto as cinco" "super vendas" da semana quanto comentários gerais sobre discos e músicos. Publicada do número 28 ao 80, "Discos" dava maior destaque às produções da DICAP e da IRT ${ }^{17}$, as duas gravadoras ligadas ao governo da UP.

Após novas mudanças, foi criada no número 95 a seção "Disco notas", que trazia comentários sobre discos recém-lançados, também privilegiando a DICAP e a IRT. Nas quatro únicas edições que trazem "Disco notas", podemos encontrar elogios a músicos da NCCh, como Tito Fernández ("um dos mais populares (para não dizer o mais popular deste momento), do meio musical”) e Víctor Jara ("um dos melhores criadores musicais do movimento da Nova Canção Chilena”) (L.J., 1973, p. 7).

\footnotetext{
${ }^{16}$ Em algumas edições, a lista é composta por 4 ou 6 itens. Nos números 53 a 59, 73 e 75 as "super vendas" não são publicadas.

17 Indústria de Rádio e Televisão (IRT) foi o nome dado à companhia RCA Victor após sua nacionalização, em fevereiro de 1971. Trata-se de uma das primeiras medidas tomadas pelo governo da UP, que, através da CORFO, adquiriu 51\% das ações da empresa.
} 
Por fim, Ramona publicou letras e cifras de canções desde a oitava edição. No número 17, elas foram reunidas na seção “¡A cantar todos!”, que passou a ser assinada pelo músico Pedro Yáñez no número 45. Verifica-se que, desde que Yáñez assumiu, predominaram canções pertencentes a músicos da NCCh - como é o caso do próprio autor. Também figuravam temas de movimentos internacionais afins, como a Nova Canção uruguaia; e outros de cantores "alienados" na perspectiva da esquerda, como Tony Ronald e Tormenta (SCHMIEDECKE, 2017, p. 255-256).

As relações entre Ramona e a NCCh também podem ser observadas fora das seções dedicadas à música. É o caso, por exemplo, de uma promoção realizada pela revista em que o público deveria votar no melhor cantor e no melhor jogador de futebol do país. Os participantes concorreriam a 500 discos single produzidos pela DICAP. A faixa do lado A, "Ramona", era interpretada em ritmo de son cubano pelos conjuntos Quilapayún e Manguaré e o lado B trazia a música instrumental "Por Chile", na qual o grupo Combo Xingú alternava os estilos de funk-rock e balada. Enquanto a letra de "Ramona" homenageava a "heroína e lutadora" Ramona Parra, a sonoridade empregada em "Por Chile" pode ser entendida como uma tentativa de "aproximar a um maior número de audiências uma mensagem política que somasse forças à Unidade Popular" (TOBAR CARARSCO, 2014, p. 37). O resultado da enquete foi publicado na $25^{\text {a }}$ edição: Tito Fernández foi o cantor vencedor, com 13.000 pontos, seguido por Víctor Jara ( 9.800 pontos) e Marcelo (expoente da balada romântica e apoiador declarado do governo; 5.000 pontos) (150 DISCOS..., 1972, p. 32).

A revista também incursionou no âmbito radiofônico, com o programa "Tiempo Joven", conduzido pelo locutor Hector Balbontin e realizado em parceria com a DICAP na rádio Magallanes, pertencente ao PC. Cucho Fernández fez uma rápida cobertura de sua primeira transmissão em "Prenda la oreja”, informando que a música havia ficado a cargo dos conjuntos Illapu e Inti-Illimani, contando também com a participação de Genaro Prieto, finalista do III Festival da Nova Canção Chilena (1971) (FERNÁNDEZ, 1972, p. 11).

O envolvimento de músicos ligados ao movimento com Ramona é igualmente perceptível em uma matéria dedicada ao evento comemorativo do primeiro aniversário da revista, no qual "se escutaram os melhores e mais populares artistas do momento", 
incluindo Ángel Parra, Tito Fernández, Víctor Jara e Huamarí. A matéria reafirmava que um dos objetivos de Ramona seria "destacar a atividade que eles - e outros - realizam no campo da canção e da cultura" (GRACIAS, 1972, p. 36).

Apesar da ênfase dada ao movimento da NCCh, a revista se abriu a outros estilos musicais, não apenas nos rankings e nos comentários gerais sobre discos, mas também em artigos sobre temas variados, como festivais da canção mais comerciais, tango e rock. Tal abertura também pode ser notada em matérias que realizavam balanços da produção musical nacional e convidavam uma gama variada de especialistas a expressarem suas opiniões - inclusive figuras distantes da esquerda, procurando abarcar diferentes pontos de vista. Conforme indicado anteriormente, entendo que esta atitude observada nas seções culturais buscava contrabalançar o conteúdo político explícito que predominava no restante da publicação, contribuindo para que jovens não identificados com o PC também se interessassem por ela.

\section{Considerações Finais}

Com o crescimento experimentado pelas Juventudes Comunistas do Chile em fins dos anos 1960, ganhou força a ideia de que “A juventude é uma força dinâmica, sensível, receptiva, capaz de inclinar a balança social em determinados momentos" (PARTIDO COMUNISTA DE CHILE, 1969, p. 68). Daí a necessidade sentida pelo PC de criar novos veículos de comunicação voltados a este público, como a gravadora DICAP e a revista Ramona.

Considerado "um verdadeiro exemplo do que deve ser o compromisso revolucionário" - conforme se referiu Ramona ao conjunto Inti-Illimani (INTI-ILLIMANI, 1973, p. 5) -, o movimento da NCCh ocupou um lugar de destaque no catálogo da gravadora e nas páginas da revista no período anterior ao golpe militar de 11 de setembro de 1973. No primeiro caso, observa-se que alguns músicos estiveram diretamente envolvidos com a empresa - como é o caso de Eduardo Carrasco, que foi seu primeiro diretor artístico; e do Inti-Illimani, que "apadrinhou” o conjunto Illapu, possibilitando que ele gravasse ali seu LP de estreia. Fosse produzindo discos, fosse promovendo 
apresentações (via ONAE), a DICAP constituiu-se na principal difusora do repertório da NCCh no país e no exterior. No caso de Ramona, embora o conteúdo artístico não fosse predominante na publicação, a parte dedicada à música dava preferência ao movimento, cujos expoentes eram apontados como “ídolos positivos” para a juventude.

Após o golpe militar, as redes construídas por meio do PC se mostraram fundamentais para a sobrevivência da NCCh no exílio. Artistas como Quilapayún e IntiIllimani conseguiram se estabelecer no cenário musical europeu, participando de festivais e gravando LPs por selos ligados à esquerda política, os quais eram distribuídos para diferentes países pela DICAP.

É importante ressaltar, porém, que o apoio dado pelo Partido não se deu de maneira igualitária para todo o repertório abrangido na denominação "Nova Canção Chilena". De acordo com os pesquisadores Carlos Valladares e Manuel Vilches, Rolando Alarcón "não tinha as portas abertas" na DICAP, tendo gravado apenas um LP por este selo. Segundo Carvajal, as razões seriam eminentemente artísticas: "Alarcón não era do meu gosto [...] A meu ver ele estava mais atrás em termos criativos do que os Parra e Manns, não tinha mais o impulso criativo de antes" (VALLADARES; VILCHES, 2009, p. 149). Alguns autores questionam tal explicação, indicando que outros fatores estariam envolvidos no distanciamento tomado pelo Partido em relação ao músico, como sua homossexualidade e seu pertencimento ao universo da peña Chile Ríe y Canta, "que tinha escassa relação com a 'oficialidade' da DICAP” (VALLADARES; VILCHES, 2009, p. 149). Outro exemplo que chama atenção é o de Patricio Manns, que nunca gravou discos pelo selo - possivelmente devido à sua militância no Movimento de Esquerda Revolucionário (MIR), o qual se manteve à esquerda do governo de Allende e criticou abertamente a linha política do PC.

Casos como os anteriores apontam para a importância de relativizar a associação automática frequentemente estabelecida pela bibliografia entre movimento e Partido. Ao invés de naturalizá-la, o presente artigo buscou contribuir para compreender como se deu, de fato, esta relação. Trata-se de um pequeno passo em um caminho ainda longo por percorrer, pois muitas questões permanecem abertas. Seria interessante, por exemplo, perguntar pelos nomes e projetos que ficaram de fora das políticas partidárias, 
devendo contar com outros canais de produção e divulgação. Nesse sentido, longe de oferecer um panorama acabado, espero ter chamado atenção para a relevância da problemática proposta, estimulando o desenvolvimento de outros trabalhos que venham a reiterar ou relativizar as conclusões aqui apresentadas.

\section{Referências}

150 DISCOS iy se acabó! Ramona, Santiago, n. 25, p. 32, 18 abr. 1972.

AGUILERA, Pablo. Tito Fernández: un recital de lágrimas y risas. Onda, Santiago, n. 45, p. 32-33, 22 maio 1973.

ALBORNOZ, César. La experiencia televisiva en el tiempo de la Unidad Popular: la caldera del diablo. In: PINTO VALLEJOS, Julio (Ed.). Fiesta y drama: nuevas historias de la Unidad Popular. Santiago: LOM, 2014, p. 143-172.

CARRASCO, Eduardo. Quilapayún: la revolución y las estrellas. Santiago: RIL, 2003.

CARVAJAL, Juan. Objetivos de DICAP. El siglo, Santiago, p. 7, 9 dez. 1972.

DALMÁS, Carine. Brigadas muralistas e cartazes de propaganda da experiência chilena (1970-1973). 2006. Dissertação (Mestrado em História) - Faculdade de Filosofia, Letras e Ciências Humanas, Universidade de São Paulo, São Paulo, 2006.

DALMÁS, Carine. Frentismo cultural em prosa e verso: comparações, conexões e circulação de ideias entre comunistas brasileiros e chilenos (1935-1948). 2013. Tese (Doutorado em História) - Faculdade de Filosofia, Letras e Ciências Humanas, USP, São Paulo, 2012.

DICAP: discos con otros jockeys. Ahora, Santiago, n. 11, p. 43-44, 29 jun. 1971.

FAIRLEY, Jan. La nueva canción chilena 1966-1976. 1977. Tese (Bachelor of Philosophy in Latin American Studies) - Linacre College, Oxford University, Oxford, 1977.

FERNÁNDEZ, Cucho. Prenda la oreja. Ramona, n. 10, p. 50, 31 dez. 1971. 
FERNÁNDEZ, Cucho. Prenda la oreja. Ramona, Santiago, n. 19, p. 11, 7 mar. 1972.

GARCIA, Tânia Costa. Nova Canção: manifesto e manifestações latino-americanas no cenário político mundial dos anos 60. In: CONGRESSO DA IASPM-AL, VI, 2005, Buenos Aires. Anais... Buenos Aires: IASPM, 2005. p. 1-11. Disponível em: <http://www.iaspmal.net/wp-content/uploads/2012/01/costagarcia.pdf >. Acesso em: 29 abr. 2015.

GILMAN, Claudia. Entre la pluma y el fusil. Buenos Aires: Siglo XXI, 2003.

GOMES, Caio de Souza. Quando um muro separa, uma ponte une: conexões transnacionais na canção engajada na América Latina (anos 1960/70). São Paulo: Alameda, 2015.

GRACIAS amigos. Ramona, Santiago, n. 54, p. 34-36, 7 nov. 1972.

INTI-ILLIMANI: un ejemplo. Ramona, Santiago, n. 70, p. 5, 27 fev. 1973.

JARA, Joan. Canção inacabada: a vida e a obra de Victor Jara. Rio de Janeiro: Record, 1998.

JARA, Víctor. La canción protesta. El Siglo, Santiago, p. 11, 30 abr. 1970.

L. J. Disco notas. Ramona, Santiago, n. 96, p. 7, 29 ago. 1973.

LAS RESPUESTAS de Manuel. Ramona, Santiago, n. 8, p. 34, 17 dez. 1971.

MIRANDA MEZA, Gustavo. Cuando la cultura se escribe con la guitarra: El sello DICAP y la política de las Juventudes Comunistas, Chile. 1968-1973. In: CONGRESO CHILENO DE ESTUDIOS EN MÚSICA POPULAR, I, 2011, Santiago. Anais... Santiago: ASEMPCh, 2012. Disponível em: <http://www.congresos.asempch.cl/congreso2011/actas/miranda >. Acesso em: 11 maio 2013. p. 93-102.

NAPOLITANO, Marcos. A arte engajada e seus públicos (1955/1968). Estudos Históricos, Rio de Janeiro, n. 28, p. 103-124, jan./dez. 2001.

NAPOLITANO, Marcos. A relação entre arte e política: uma Introdução teóricometodológica. Temáticas, Campinas, n. 37/38, p. 25-56, jan./dez., 2011.

OLIVARES, E. DICAP: Discoteca del Cantar Popular. El Musiquero, Santiago, n. 141, p. 2-5, jun. 1971. 
ONAE. Ya pisa fuerte. Ramona, Santiago, n. 42, p. 5, 15 ago. 1972.

OSSORIO, Jose M. Encuentro de la canción protesta. Casa de las Américas, Havana, n. 45, p. 139-144, nov./dez. 1967.

PADILLA, Alfonso. Entrevista II [4 dez. 2015]. Entrevistadora: Natália Schmiedecke. Helsinki, Universidade de Helsinki, 2015. 1 arquivo .mp3 (140 min.).

PANORAMA. Ramona, Santiago, n. 40, p. 7, 1 ago. $1972 a$.

PANORAMA. Ramona, Santiago, n. 43, p. 7, 22 ago. 1972b.

PARTIDO COMUNISTA DE CHILE. XIV intervenciones y resoluciones del XIV Congreso (celebrado entre el 23 y el 29 de noviembre de 1969). Santiago: [s.n.], 1969.

PARTIDO COMUNISTA DE CHILE. La revolución chilena y los problemas de la cultura. Documentos de la Asamblea Nacional de Trabajadores de la Cultura del Partido Comunista, realizada los días 11-12 de septiembre. Santiago: [s.n], 1971.

RODRÍGUEZ AEDO, Javier. La Nueva Canción Chilena: un ejemplo de circulación musical internacional (1968-1973). Resonancias, Santiago, v. 20, n. 39, p. 63-91, jul./nov. 2016.

ROLLE, Claudio. La nueva canción chilena, el proyecto cultural popular y la campaña de gobierno de Salvador Allende. In: CONGRESSO DA IASPM-AL, III, 2000, Bogotá. Anais... Bogotá: IASPM, 2000. Disponível em:

$<$ http://www.oocities.org/portaldemusicalatinoamericana/Rolle.pdf $>$. Acesso em: 8 ago. 2017. p. 1-13.

SCHMIEDECKE, Natália. La influencia de DICAP en la nueva canción chilena. In: KARMY, Eileen; FARÍAS, Martín (Comp.). Palimpsestos sonoros: reflexiones sobre la Nueva Canción Chilena. Santiago: Ceibo, 2014, p. 201-218.

SCHMIEDECKE, Natália. Não há revolução sem canções: utopia revolucionária na Nova Canção Chilena, 1966-1973. São Paulo: Alameda, 2015.

SCHMIEDECKE, Natália. Nuestra mejor contribución la hacemos cantando: a nova canção chilena e a questão cultural no Chile da Unidade Popular. 2017. Tese (Doutorado em História) - Faculdade de Ciências Humanas e Sociais, UNESP, Franca, 2017.

TOBAR CARRASCO, José Fabián. La canción contingente durante el gobierno de la Unidad Popular (1970-1973): analisis sobre el uso de la intertextualidad como estrategia política en la creación y recepción musical. 2014. Tesis (Licenciatura en Estetica) Facultad de Filosofía, Pontificia Universidad Catolica de Chile, Santiago, 2014. 
Santiago: Quimantú, 2009.

VILLAÇA, Mariana. Cinema cubano: revolução e política cultural. São Paulo: Alameda, 2010.

Recebido em 17/08/2017 Aprovado em 06/12/2017 